Mosul Journal of Nursing, Vol. 7, No. 1, 2019 ( 30-36 )

Mosul Journal of Nursing

www.mjn.mosuljournals.com

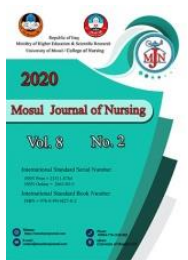

\title{
Assessment of Female Nursing Students knowledge and practice about Breast Self-Examination in Mosul University
}

Article information

Article history:

Received April 11, 2019

Accepted May 5, 2019

Available online June 1, 2019

\section{ABSTRACT:}

Background and aim: Breast self-examination is a screening method and valuable tool used in an attempt to detect early breast cancer among women. The study aimed to assess the level of knowledge and practice of nursing female students about breast self-examination in Mosul university.

Materials and method: A descriptive study design was adopted in the study. A systemic random sample of 100 female nursing student were selected in this descriptive study, they collected as 25 student from each of the under graduated teaching classes, the study conducted in a period from October 2017 to the end of march 2018. Data were collected by using a questionnaire constructed to meet the study objective, it is consisted from five parts, the first one concerned with socio demographic data, second part represent personal history of the participants, third part reflect knowledge and practice of them about breast self-examination that reflect their awareness toward this subject, fourth part identify the source of their knowledge and practice, last part demonstrate the main barriers and limitations caused failure in conducting this examination.

Results: The study founded that $46 \%$ of the sample were at 20-21years old, $91 \%$ of them from urban residence, about $66 \%$ of the sample having healthy nutritional habits, history of hormonal and menstrual disturbance was found among $30 \%$ of the sample, about $73 \%$ of female nursing students aware of breast cancer risk that represented by their knowledge about breast self-examination, but only $23 \%$ of them conducting the examination regularly, this is due to their feeling of wellness and also because of absence of obligation in conducting the examination.

Conclusion: the majority of study sample were from (20-21) age group, with urban residence Two third of the sample having healthy balance diet, while about one third of sample experience hormonal and menstrual disturbance.

Recommendation The study recommend for improvement of the practical aspects of breast selfexamination via improvement of the teaching curriculum and through mass media

Key Words : Breast self-examination, knowledge, practice , Breast cancer

\footnotetext{
${ }^{1}$ Lecturer / College of Nursing / University of Mosul

${ }^{2}$ Instructor / College of Nursing / University of Mosul
} 


\section{Mosul Journal of Nursing, Vol. 7, No. 1, 2019 ( 30-36 )}

\section{INTRODUCTION}

Breast problems are extremely common Comprising one in six of all general surgery Worldwide there are 57000 new cases of breast cancer per year (Kakabra and Abdul Saheb, 2012). The incidence of breast cancer has been increasing since the 1950. Presently, one of every eight woman will acquire breast cancer some time in life, the chance of dying is about one in thirty five. Risk factors include age, personal or family history, early age of menarche, late age of menopause, never having children, or having child first after30years (Mary and Melanie, 2011).The key to successful treatment, however, lies in early detection by monthly breast self-examination (BSE) (Smith et. al., 2008). Breast selfexamination is a screening method and valuable tool used in an attempt to detect early breast cancer, involves the woman herself looking at and feel each breast for possible lump, distortions or swelling (Bevers et.al., 2009). By doing BSE regularly, women should be familiar with how their breasts normally appear and feel then report any breast changes promptly to their health care providers (Oussama, 2006). The American Cancer Society recommends that women, beginning in their early 20 s, be told about the benefits and limitations of BSE, it is then up to the individual woman whether to perform BSE regularly, irregularly, or not at all (Smith et. al., 2008). Women should continue practicing BSE throughout their lives-even during Pregnancy and after menopause (David and Debra, 2011). A correctly performed Breast Self-examination normally takes seven to ten minutes, it includes the steps:

Firstly, should know how breasts normally look. A small visual change may be an important early sign of a problem. Stand undressed from the waist up in front of a mirror with arms relaxed by sides. Compare breasts while turning from side to side. Look for any change in breast size, shape, skin texture or color. Including redness, dimpling, puckering or retraction. Look for nipple discharge. Some discharge can be normal, due to hormones or medication.

However, all discharges should be reported to your doctor. Note the color of the discharge, whether it came from both breasts and whether it came from one or more openings. Next, press your hands firmly on your hips and lean slightly toward your mirror as you pull your shoulders and elbows forward with a squeezing or hugging motion. Look for any change in the normal shape of your breasts. Now, bend forward at the waist, hold your head up and look in the mirror. You may notice that one breast is larger than the other and this is normal. Also Looking in the mirror, raise your arms and rest your hands behind your head. This allows you to see the underside of your breasts. Now Place your left hand on your waist, roll your shoulder forward and reach into your underarm area and check for enlarged lymph nodes (small glands that fill with fluid when you have an infection). An enlarged node would feel like a corn kernel or a bean. Also check the area above and below the collar bone. Repeat on the right side. Raise your left arm. Use the pads of three or four fingers of your right hand to examine your left breast. Use three levels of pressure (light, medium, and firm) while moving in a circular motion. Check your breast area using a set pattern. You can choose (1) lines, (2) circles or (3) wedges. In Lines Beginning at the outer edge of your breast move your fingers downward using a circular motion until they are below the breast. Then move your fingers slightly toward the middle and slowly move back up. Go up and down until you go over the entire breast area. While in Circles Beginning at the outer edge of your breast use the flat part of your fingers, moving in circles slowly around the breast. Gradually make smaller and smaller circles toward the nipple. Be sure to cover the entire breast and check behind the nipple. The last Wedges Starting at the outer edge of the breast, move your fingers toward the nipple and back to the edge. Check your entire breast, covering one wedge-shaped area at a time. You should not lift your fingers while feeling the breast to make sure no area is missed.

Whatever method you choose, make sure to cover the entire area including the breastbone, collarbone, upper chest area, and bra line. Pay special attention to the area between the breast and the armpit itself. Feel for any unusual lump, mass or thickening under the skin. Repeat on the right side. The last step lie flat on your back, left arm over your head and a pillow or folded towel under your left shoulder. This position flattens the breast and makes it easier 


\section{Mosul Journal of Nursing, Vol. 7, No. 1, 2019 ( 30-36 )}

to examine. Some women like to use body lotion, cream or bath powder in this step.

Menstruating women should do BSE one week after their menstrual period begins when breasts are less lumpy and tender. Pregnant women should check their breasts on the same day each month. Breast feeding mother should check their breasts on the same day each month after emptying their breasts. Women who take hormone replacement therapy should do BSE on the same day every month.The effectiveness of BSE is determined by the woman's ability to perform the procedure correctly (Patricia and Rueckert, 2011). The community health nurse must determine the need for a screening program by identifying high risk population, determining risk status of individuals or Community based on analysis of sociodemographist (Kakabra and Abdul Saheb, 2012). The nurse also play an import role in BSE education, a modality used for the early detection of breast cancer. BSE can be taught in a variety of settings either one -to -one or in a group (Abdullah, 2004). The U.S. preventive services take force has found evidence that suggest BSE do lower the risk of death from breast cancer. Therefore ,BSE should not be used in place of, but in addition to, clinical breast examination that is provided by a health care provider every three years for women in their 20s and 30s, and every year for women ages 40 and older with mammography (Patricia and Rueckert, 2011). The study aims to assess female nursing students knowledge and practice about breast self-examination and to assess the personal history of the study sample that related to breast problem. It also aimed to identify the level of knowledge of the study sample, to determine the source of the knowledge of the female nursing students about breast selfexamination. In addition, the study aims to identify the limitation and barriers against conducting breast self-examination by the study sample, Assess student practice regarding breast self-examination.

\section{MATERIALS AND METHOD}

At the beginning of the study an ethical agreement was obtained from female nursing students. A descriptive study design was adopted in the study to assess female students regarding their knowledge and their practice toward breast self-examination. This study was carried out in the Nursing College / University of Mosul. The investigators selected a target group of 100 women who were under graduated female nursing students, from the first, second, third and fourth stages of the college with a different age groups ranging from (18-25) year. 25 students were selected from each class by using systemic random sampling technique. The study conducted out through $20^{\text {th }}$ October 2017 to $1^{\text {st }}$ April 2018. In order to achieve the desired aim of the present study for assessment of female nursing students knowledge and practice about breast self-examination, a special tool was adopted in this study, this tool consisted of five parts, the first part was concerned with socio demo graphic data that is related to the female students who were selected to form the tool consisted of many items that is reflect the personal history of the participants as age of menarche, family history of breast disease, history of menstrual and hormonal disturbance, personal history of breast about their problem or lump, type of nutrition and history of overweight. The third part is a question focused on knowledge and practice regarding breast self-examination and about their steps in conducting it with two scale options, fourth part concentrated on the source of their knowledge and skills to conduct this health promoting examination. The fifth part organized to be concerned with items regarded as factors or barriers that impede or cause failure to conduct breast self-examination, it is in the form of a checklist. The tool was rearranged and reorganized according to the opinion of a panel of experts in the Clinical nursing department in order to be valid and suitable with the aim and objectives of the study. The reliability was obtained by applying test and retest of the tool on a small sample consisted of 10 female students who were excluded from the whole sample of the study, computation of correlation coefficient was applied and revealed a value of (0.84) which is statistically acceptable at the level (0.05). 
Mosul Journal of Nursing, Vol. 7, No. 1, 2019 ( 30-36 )

\section{RESULTS}

Table (1): Socio-demographic characteristics of the study sample:

\begin{tabular}{c|cc}
\hline Age & NO. & \% \\
\hline 18-19 years & 32 & 32 \\
20-21 year & 46 & 46 \\
22-23 year & 19 & 19 \\
24 and above & 3 & 3 \\
total & 100 & 100 \\
Address & & \\
Urban & 91 & 91 \\
Rural & 9 & 9 \\
total & 100 & 100 \\
Marital Status & & \\
Unmarried & 90 & 10 \\
Married & 10 & \\
total & 100 &
\end{tabular}

Table (2): Personal and family history of the study sample:

\begin{tabular}{l|llll}
\hline \multicolumn{1}{c|}{ Items } & Yes & \multicolumn{3}{c}{ No } \\
& NO. & \% & NO. & \% \\
\hline Family history of breast disease or breast cancer. & 6 & 6 & 94 & 94 \\
Hormonal and menstrual $\quad$ disturbance. & 30 & 30 & 70 & 70 \\
History of breast lump. & 4 & 4 & 96 & 96 \\
Previous medical or surgical conditions. & 2 & 2 & 98 & 98 \\
History of healthy diet. & 66 & 66 & 34 & 34 \\
History of abnormal gaining weight. & 7 & 7 & 93 & 93 \\
\end{tabular}


Table (3): Distribution of the study sample according to their knowledge and practice about breast self-examination $. \mathbf{n}=\mathbf{1 0 0}$

\begin{tabular}{l|llllll}
\multicolumn{1}{c|}{ Items } & Yes & & NO & & $\begin{array}{l}\text { Mean } \\
\text { scores }\end{array}$ \\
& NO. & \% & NO. & \% & \\
\hline $\begin{array}{l}\text { 1.Do you know what is breast self-examination and its } \\
\text { steps. }\end{array}$ & 73 & 73 & 27 & 27 & $1.73 *$ \\
$\begin{array}{l}\text { 2. Do you conduct breast self-examination monthly. } \\
\text { 2. }\end{array}$ & 23 & 23 & 77 & 77 & 1.23
\end{tabular}

Table (4) Source of knowledge and skills needed to conduct BSE by the study sample:

\begin{tabular}{l|ll}
\hline Source & NO. & \% \\
\hline 1.Newspaper and magazines. & 7 & 7 \\
2. Mass media. & 31 & 31 \\
3. Seminars or training course. & 15 & 15 \\
4. Colleagues and relatives. & 11 & 11 \\
5. Internet. & 2 & 2 \\
6. Teaching curriculum. & 28 & 28 \\
7. Medical and nursing staff. & 6 & 6
\end{tabular}

Table (5):Barriers and limitations against conducting BSE among the study sample:

\begin{tabular}{c|cc}
\hline Barriers & NO. & \% \\
\hline 1.Egnorance of examination steps. & 23 & 23 \\
2.Absence of previous training. & 32 & 32 \\
3. Shortage of time. & 42 & 42 \\
4.Fear from the result. & 44 & 44 \\
5. Careless about your health. & 27 & 27 \\
6.Lack of obligation . & 69 & 69 \\
7.Poor facilities. & 37 & 37 \\
8.Shyness. & 47 & 47 \\
9. Painful examination steps. & 11 & 11 \\
10.Having healthy breast. & 61 & 61 \\
11.Egnorance of the time of examination. & 42 & 42 \\
12. Difficult examination steps. & 23 & 23
\end{tabular}




\section{Mosul Journal of Nursing, Vol. 7, No. 1, 2019 ( 30-36 )}

\section{DISCUSSION}

Today, women in Iraq live with a lot of challenges ,they are always fighting against malignant Diseases ,breast cancer is the most prevalent cancer among women and it is started to take new epidemiological pattern by the affection of the youngest group of women. As this challenge increases the key to safe life is to detect the disease in its early stages, this Can be achieved by conducting a regular breast selfexamination by the women, especially The risky group of them. The present study concentrated on how much the female nursing students know and perform breast selfexamination and how much they are aware of its importance in detecting the disease.

Table (1) shows that the majority of the participants were aged between (20-21) years, $91 \%$ of them from urban residence. $90 \%$ of the sample were single, and this is attributed to our culture and tradition in which few families let their girls get married during the nursing study, this is agree with other investigators Kakabra and Abdul Saheb, 2012). Although the investigator selecting same number which is 25 from each class ,this because their age not similar when they enrolled to nursing education and because of failure of some of them from passing from class to another, in table (2) show that $66 \%$ of the study sample taking healthy diet but $30 \%$ of the total sample gave history of hormonal and menstrual disturbance, while only $2 \%$ of them had history of medical and surgical breast conditions. Personal history of the study sample is of importance because it reflect their lifestyle and represented by menstrual history and family history of breast lump, manner of nutrition (Smiltzer et $a l ., 2004)$. The main result in this study reflect how much female nursing students aware about BSE, in table (3) show about $73 \%$ of them know the exact steps of BSE, this knowledge derived mainly from their teaching curriculum in nursing college. In table (4) shows the source of knowledge and skill of female nursing students to perform breast self-examination ,which was community mass media in $31 \%$ and nursing teaching curriculum in $28 \%$, this result go with what is found by other researcher (Osime et. al., 2008).. In table (3) show Although majority of our sample know about the steps of BSE but only $23 \%$ of them conduct the examination regularly .but not agree with the result of a study conducted in Turkey (Beydag,2007) which founded that50\% of female university students did not know how to perform BSE . in table (5) the study shows that $69 \%$ of the barriers against conducting BSE arises from absence of obligation, having healthy breast among $61 \%$, and shyness in $47 \%$ of the sample (Ilaate , 2000). The main causes arises beyond this attitude and regarded as barrier against conducting BSE in spite of their good knowledge were the absence of obligation in performing the examination in a continuous regular manner, also because of their felling of wellness and absence of breast problems. This result empower us to improve the felling of responsibility on their breast health among female students and push them to be familiar with how their breast look and feel through monthly BSE in spite of the absence of the disease (Ewles and Simnett,2003).

\section{Conclusion:}

Majority of study sample were from (20-21) age group, with urban residence. About two third of the sample having healthy balance diet, while one third of sample experience hormonal and menstrual disturbance. Majority of female nursing student are aware of breast cancer risk because they are know the general information about breast self-examination, but only one quarter of sample conduct the steps regularly, in addition to there is limitation and barrier against conducting breast self-examination regularly was the feeling of healthy and lack of obligation for performing the health promoting activity. The Student found mass media and nursing teaching curriculum were the source of their knowledge.

\section{Recommendation}

The study suggest further improvement of the practical performance in conducting BSE and pay attention for regular examination of their breast. Additionally, the result suggest a need to include a training course of BSE in teaching curriculum starting from preparatory schools then higher education with special concentration on the practical steps of the examination . Community health nurse should be encouraged to get involvement in breast cancer prevention specially for those highly risk group to achieve early detection and 


\section{Mosul Journal of Nursing, Vol. 7, No. 1, 2019 ( 30-36 )}

treatment. The Mass media in T.V and Radio should be done by professional health workers that emphasized on a practical aspect of breast self-examination for women in all age groups which can positively affect themselves, their families and community

\section{References:}

Diana H. Fairleg. (2009). Obstetrics and Gynecology, breast diseases. ( $3^{\text {rd }}$ ed.). USA. P.p. $262-265$

Kakabra, S.; and Abdul Saheb, S. (2012). Identify the level of female students knowledge toward breast self-examination and breast cancer risk factors. $10^{\text {th }}$ National scientific conference, college of nursing ,university of Mosul.

Mary A . Nies and Melanie McEwen. Community Health nursing, promoting the health of populations .(2011); 323-324.

Smith R, Cokkinides V ,Brawley O .Cancer screening in the United State : A review of Current American Cancer Society guidelines and cancer screening issues . (2008);58:161179.

Bevers T , Anderson B ,Bonaccio E ,Buys S,Daly $M$ and Dempsey p. Clinical practice guideline in oncology :breast cancer screening and diagnosis .Nathl compr canc Netw .(2009); $7: 1060$-1096.

Oussama M . Guideline for the early detection and screening of breast cancer .EMRO technological publication series 30 . World Health Organization, regional office for the Eastern Mediterranean, cairo .(2006).

David Z and Debra G . Screening by breast self-examination ,National cancer Institute .Washington . (2011).
Patricia A wieland and Rueckert Hartman .Maternal and child Nursing Care ,breast selfexamination; $3^{\text {rd }}$ edition ,USA. (2011); 103-106.

Gayle A .Sulik .Pink Ribbon Blues : How breast cancer culture undermines women 's, health .USA .(2012): oxford university .

Spiegal, TN.; Hill, KA.; and Warner, E. (2009). The attitudes of women with breast cancer toward clinical breast examination and Breast self-Examination. Journal of women 's Health (Larchmt). 18 (7). P.p.1019 -24.

Abdullah .A .Impact of an educational program upon women 's knowledge toward breast selfexamination .Dissertation ,Baghdad university , college of nursing ;January (2004);6:122

Smiltzer S, Bare B . Bruner and Suddarth 's text book of Medical Surgical Nursing ,10 th ed. Philadelphia, Lippincot Williams and Wilkins . $2004 ; 54-56$

Osime $\mathrm{O}$,Okje $\mathrm{O}$, Aigbekaen $\mathrm{E}$ and Aigbecaen I. Knowledge ,Attitude and Practice about Breast Cancer among Civil Servants in Benin City ,Nigeria .Anual of African Medicine . Vol. 7, No.4 2008 ;192197.

Beydag K, Karaoglan H . Effects of training for self-breast examination on Knowledge and Attitude of Nursing students .Preventive Medicine Bulletin of Turkish Armed Forces . $2007 ; 6$ : 106-111.

Ilaate M., W . Knowledge of secondary school female students on breast cancer and breast self-examination in Jaddah , Saudi Arabia. East Mediterr Health Journal .2000 , 6 ; 338-344.

Wles L and Simnett I .Health Promotion :A practical guide, $5^{\text {th }}$ ed , Edinburgh :Bailliere Tindall . $2003 ; 101$. 